\title{
Vermengingstermodinamika, magnetiese eienskappe en elektroniese struktuur vir $\mathrm{Pt}_{\mathrm{x}} \mathrm{Ni}_{1-\mathrm{x}}$-legerings
}

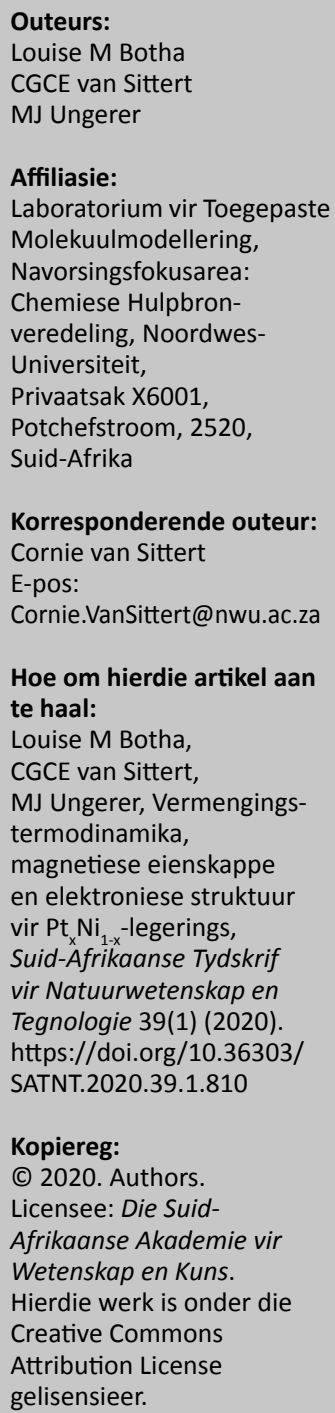

Mixing thermodynamics, magnetic properties and electronic structure of $\mathrm{Pt}_{x} \mathrm{Ni}_{1-x}$ alloys: This DFT study investigated the mixing thermodynamics, magnetic properties and related electronic structures of $\mathrm{Pt}_{x} \mathrm{Ni}_{1-x}$ alloys. The results show that $\mathrm{Pt}_{0.5} \mathrm{Ni}_{0.5}$ alloys are thermodynamically the most stable and may have the potential of being active electrocatalysts for the OER reaction.

Daar is ' $\mathrm{n}$ groeiende bekommernis oor klimaatverandering as gevolg van atmosferiese besoedeling, onder andere vrygestelde koolstofdioksied $\left(\mathrm{CO}_{2}\right)$. Gevolglik is daar'n groeiende belangstelling in die oorskakeling na alternatiewe energiebronne wat hernubaar, skoon en bekostigbaar is. Een moontlikheid is om die elektrolise van water te gebruik. Die grootste struikelblok in die kommersiële toepassing van die elektrolise van water is egter die tipe materiaal wat vir die anode, waar die suurstofontwikkelingsreaksie (OER) plaasvind, gebruik word. Platinumelektrodes lewer 'n oorpotensiaal van $1.23 \mathrm{~V}$, wat aanleiding gee tot goeie elektrokatalitiese reaktiwiteit met betrekking tot OER. Platinum is egter skaars en onbekostigbaar. Dus is die eerste ry oorgangsmetale en legerings intensief ondersoek as alternatiewe anodemateriale vir OER (Suntivich et al., 2011). Legerings wat met behulp van die byvoeging van 'n sekondêre metaal gevorm word, verander die elektroniese struktuur van die moedermetaal $(\mathrm{Pt})$. Dit lei dus tot veranderinge in die elektrokatalitiese reaktiwiteit van die moedermetaal (Suntivich et al., 2011).

Die optimale legeringsverhouding tussen platinum en nikkel is bestudeer vir platinum-/ nikkellegerings. Daarmee saam is die invloed van die legeringsverhouding op die elektroniese, termodinamiese en magnetiese eienskappe bepaal deur digtheidsfunksionaalteorie-berekeninge (DFT) en die Vienna ab-initio simulasieprogram (VASP), te gebruik. Verder is die sogenaamde site occupancy disorder (SOD) -program gebruik om simmetriese nie-ekwivalente konfigurasies te bou met twee verskillende groottes superselle, 1x1x1 en 2x2x1 (Grau-Crespo et al., 2007).

Die resultate het getoon dat die $\mathrm{Pt}_{0.5} \mathrm{Ni}_{0.5}$-vermengingskonsentrasie die stabielste vermengingskonsentrasie is. Bowendien is dit aangetoon dat die resultate, verkry van die $1 \times 1 \times 1$ superselgrootte, steeds binne aanvaarbare grense is terwyl die berekeningstyd en -koste heelwat laer is as die van die $2 \times 2 \times 1$ supersel.

Die $\mathrm{Pt}_{0.5} \mathrm{Ni}_{0.5}$-legerings is by verskillende temperature ondersoek en daar is vasgestel dat by lae temperature (ten minste $300 \mathrm{~K}$ ) net twee konfigurasies 'n waarskynlikheid van $50 \%$ het om te vorm. Verder is die elektroniese bandstruktuur, atomiese lading en spinmomentum, van bogenoemde $\mathrm{Pt}_{0.5} \mathrm{Ni}_{0.5}$-legerings ondersoek en vergelyk met die suiwer metale. In die geval van die digtheidstoestande, dra beide metale by tot die magnetiese eienskappe van die $\mathrm{Pt}_{0.5} \mathrm{Ni}_{0.5}{ }^{-}$ legerings. Hierdie waarneming is in ooreenstemming met die magnetiese eienskappe van $\mathrm{Ni}$ en Pt. Dus besit die $\mathrm{Pt}_{0.5} \mathrm{Ni}_{0.5}$-legerings magnetiese eienskappe as gevolg van die $\mathrm{Ni}$ in die legerings (Botha et al., 2019).

\section{Verwysings}

Botha LM, Santos-Carballal D, Terranova U, et al. 2019. Mixing thermodynamics and electronic structure of the $\mathrm{Pt}_{1-\mathrm{x}} \mathrm{Ni}_{\mathrm{x}}(0 \leq \mathrm{x} \leq 1)$ bimetallic alloy. RSC Advances 9(30), 16948-16954.

Grau-Crespo R, Hamad S, Catlow CRA, De Leeuw NH. 2007. Symmetry-adapted configurational modelling of fractional site occupancy in solids. Journal of Physics: Condensed Matter 19(25), 256201.

Suntivich J, May KJ, Gasteiger HA, Goodenough JB, Shao-Horn Y. 2011. A perovskite oxide optimized for oxygen evolution catalysis from molecular orbital principles. Science 334(6061), 1383-1385.

Nota: 'n Seleksie van referaatopsommings: Studentesimposium in die Natuurwetenskappe, 31 Oktober - 1 November 2019 Universiteit van die Vrystaat. Reëlingskomitee: Prof Rudi Pretorius (Departement Geografie, Universiteit van Suid-Afrika); Dr Hertzog Bisset (Suid-Afrikaanse Kernenergie-korporasie; Dr Ernie Langner (Departement Chemie, Universiteit van die Vrystaat) en Dr Wynand $\mathrm{Nel}$ (Departement Rekenaarwetenskap en Informatika, Universiteit van die Vrystaat). 